\title{
BIODIESEL: PARÂMETROS DE QUALIDADE E MÉTODOS ANALÍTICOS
}

\author{
Ivon Pinheiro Lôbo e Sérgio Luis Costa Ferreira \\ Departamento de Química Analítica, Instituto de Química, Campus Universitário de Ondina, Universidade Federal da Bahia, \\ 40170-290 Salvador - BA, Brasil
}

Rosenira Serpa da Cruz*

Departamento de Ciências Exatas e Tecnológicas, Universidade Estadual de Santa Cruz, Rodovia Ilhéus/Itabuna, km 16, 45662-000 Ilhéus - BA, Brasil

Recebido em 19/8/08; aceito em 20/1/09; publicado na web em 14/7/09

\begin{abstract}
BIODIESEL: QUALITY PARAMETERS AND ANALYTICAL METHODS. The establishment of quality standards for biodiesel was a key step to win the confidence of the market and the automotive industry, thus ensuring the success of the new fuel. In this review are presented standard methods and other analytical methods suggested for analysis of biodiesel. The methods of analysis were divided into groups according to information that may be provided on the contaminants from the raw material of the production process, the molecular structures of biodiesel and its degradation during storage.
\end{abstract}

Keywords: transesterification; biofuels; quality parameters.

\section{INTRODUÇÃO}

Suprir a demanda energética mundial tem sido um grande desafio para nossa sociedade. ${ }^{1}$ A contínua elevação do preço do barril de petróleo e as questões ambientais associadas à queima de combustíveis fósseis também têm contribuído para colocar a humanidade frente à necessidade de novas fontes energéticas. $\mathrm{O}$ uso em larga escala da energia proveniente da biomassa é apontado como uma grande opção que poderia contribuir para o desenvolvimento sustentável nas áreas ambiental, social e econômica. ${ }^{2}$ Antes mesmo do diesel de petróleo, os óleos vegetais foram testados e utilizados como combustíveis nos motores do ciclo diesel. Por razões tanto econômicas quanto técnicas, estes deram lugar ao diesel de petróleo. ${ }^{3} \mathrm{O}$ baixo preço e a oferta dos derivados de petróleo, na época, influenciaram decisivamente na escolha pelo diesel mineral.

O biodiesel é um exemplo, já em aplicação, do emprego da biomassa para produção de energia. Este apresenta vantagens sobre o diesel de petróleo, ${ }^{4}$ pois não é tóxico e é proveniente de fontes renováveis, além da melhor qualidade das emissões durante o processo de combustão. ${ }^{5}$ Embora o biodiesel forneça uma quantidade de energia cerca de $10 \%$ menor que o diesel de petróleo, seu desempenho no motor é praticamente o mesmo no que diz respeito à potência e ao torque. ${ }^{6}$ Por apresentar maior viscosidade, o biodiesel proporciona maior lubricidade que o diesel mineral, logo, tem-se observado redução no desgaste das partes móveis do motor. Por outro lado, o biodiesel possui estruturas moleculares mais simples que o seu precursor, os triglicerídeos, logo, sua viscosidade é comparativamente menor, apresentando maior eficiência de queima, reduzindo significativamente a deposição de resíduos nas partes internas do motor. ${ }^{7}$

O biodiesel é uma mistura de alquilésteres de cadeia linear, obtida da transesterificação dos triglicerídeos de óleos e gorduras com álcoois de cadeia curta (Figura 1), esta reação tem como coproduto o glicerol.

Dentre os álcoois empregados na transesterificação de óleos e gorduras, os mais utilizados são metanol e etanol. O metanol é mais amplamente aplicado na produção de biodiesel em escala comercial e, por ser mais reativo, implica em menor temperatura e tempo de reação. O etanol, além de ter produção consolidada no Brasil, é con-

\footnotetext{
*e-mail: roserpa@uesc.br
}

sideravelmente menos tóxico, é renovável e produz biodiesel com maior número de cetano e lubricidade. Uma grande desvantagem do etanol está no fato deste promover uma maior dispersão da glicerina no biodiesel, dificultando a sua separação. Para a obtenção de maiores rendimentos na reação de transesterificação costuma-se utilizar excesso de álcool e remoção da glicerina. Para o metanol, a razão molar comumente empregada é de 6:1, enquanto que para o etanol, a razão é de $9: 1$ a 12:1. ${ }^{8}$

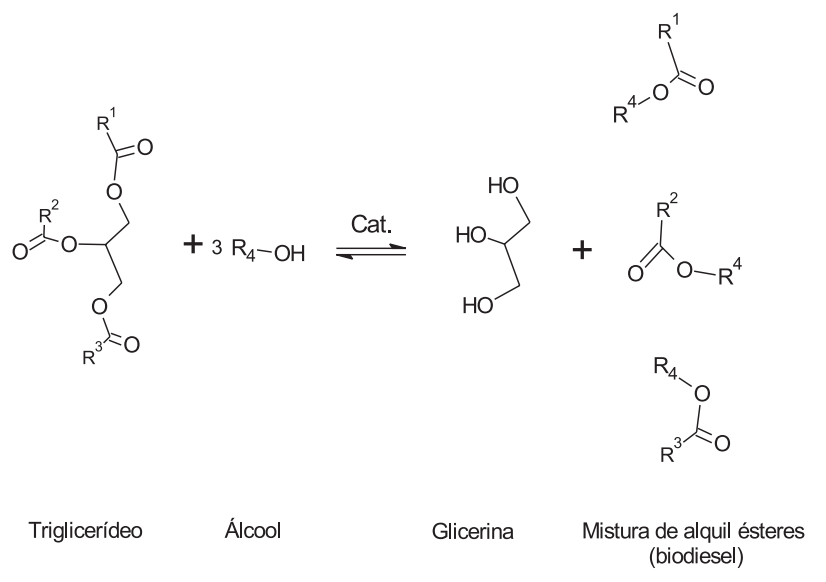

Figura 1. Reação de transesterificação de triglicerídeos

A reação de transesterificação de óleos ou gorduras é realizada na presença de catalisadores ácidos, básicos ou enzimáticos. Os catalisadores mais empregados são os catalisadores homogêneos alcalinos, que são mais eficientes, promovendo altos rendimentos. Dentre estes, os alcóxidos são mais ativos, resultando em rendimentos superiores a $98 \%$ na reação de transesterificação, no entanto são mais sensíveis à presença de água. Os hidróxidos de sódio e de potássio, embora menos ativos, apresentam menor custo, promovem rendimentos satisfatórios e têm sido mais amplamente empregados. ${ }^{9}$

Várias pesquisas têm sido realizadas no desenvolvimento de catalisadores heterogêneos, ${ }^{10}$ básicos, ácidos e enzimáticos, ${ }^{11}$ para a transesterificação de óleos e gorduras, buscando as vantagens como 
a possibilidade de reutilização do catalisador e a simplificação do processo de purificação do biodiesel, pois os catalisadores heterogêneos são facilmente removidos por um simples processo de filtração, reduzindo assim a geração de efluentes.

\section{MÉTODOS ANALÍTICOS PARA AVALIAÇÃO DA QUALIDADE DO BIODIESEL}

Para garantir a qualidade do biodiesel é necessário estabelecer padrões de qualidade, objetivando fixar teores limites dos contaminantes que não venham prejudicar a qualidade das emissões da queima, bem como o desempenho, a integridade do motor e a segurança no transporte e manuseio. Devem ser monitoradas também possíveis degradações do produto durante o processo de estocagem.

A Áustria foi o primeiro país a definir e aprovar os padrões de qualidade para biodiesel, aplicados a ésteres metílicos de colza. Subsequentemente, padrões de qualidade foram sendo estabelecidos em outros países. ${ }^{8}$ Atualmente o padrão de qualidade americano, elaborado pela ASTM (American Society of Testing and Materials), através da norma ASTM D6751, e o estabelecido na União Européia através da norma EN 14214 do Comitê Europeu de Normalização (Comité Européen de Normalisation - CEN) figuram como os mais conhecidos e são geralmente usados como referência ou base para outros padrões. ${ }^{12}$

No Brasil, a Lei 11097/05 instituiu a obrigatoriedade da adição de $2 \%$ de biodiesel ao diesel (mistura B2) a partir de janeiro de 2008 e torna obrigatórias as misturas de 5\% até 2013. Antecipando as previsões, o Conselho Nacional de Políticas Energéticas (CNPE), através de sua Resolução $n^{\circ} 2 / 2008$, tornou obrigatória a adição de $3 \%$ de biodiesel ao diesel (mistura B3) a partir de $1^{\circ}$ de julho deste ano. Esta medida, além de fortalecer a indústria nacional e reduzir a participação do diesel mineral na matriz energética nacional, visa também escoar a produção nacional de biodiesel. As especificações do B100, a ser misturado com o diesel mineral, são estabelecidas pela Agência Nacional do Petróleo, Gás Natural e Biocombustíveis (ANP), através da Resolução n ${ }^{\circ} 07$ de 2008 (RANP 07/08) que substituiu a Resolução ${ }^{\circ} 42$ de 2004, tornando os critérios de avaliação da qualidade do biodiesel brasileiro mais restritivos. Os padrões de qualidades presentes nesta resolução foram constituídos com base nas normas ASTM D6751 e EN 14214 (Tabela 1). A mistura óleo diesel/biodiesel tem sua especificação estabelecida pela resolução ANP 15/2006.

Entre os parâmetros instituídos nas normas, encontram-se os que são provenientes da normatização do diesel mineral e os que foram originados de análises de os óleos vegetais, comumente utilizados na indústria óleoquímica. Parâmetros como viscosidade cinemática, ponto de fulgor e cinzas sulfatadas, embora tenham origem na normatização do diesel mineral, fornecem resultados bastante esclarecedores quanto à qualidade do biodiesel, conforme será descrito a seguir.

A qualidade do biodiesel pode sofrer variações conforme as estruturas moleculares dos seus ésteres constituintes ou devido à presença de contaminantes oriundos da matéria prima, do processo de produção ou formados durante a estocagem do biodiesel. As estruturas moleculares dos ésteres podem variar tanto no tamanho da cadeia carbônica, quanto na quantidade e posição de insaturações ou mesmo devido à presença de agrupamentos na cadeia, a exemplo da hidroxila ligada à cadeia carbônica do alquiléster derivado do ácido ricinoléico proveniente da mamona. Contaminantes procedentes da matéria prima, a exemplo do fósforo, enxofre, cálcio e magnésio, podem também ser encontrados no biodiesel. Dependendo da eficiência do processo de produção do biodiesel, podem estar presentes em maior ou menor quantidade: glicerina livre, glicerídeos não reagidos, sabões, álcool residual, resíduos de catalisadores e água. A absorção de umidade e os processos de degradação oxidativa durante o armazenamento do biodiesel contribuem para a presença de água, peróxidos e ácidos carboxílicos de baixa massa molecular. Neste trabalho, os métodos analíticos para avaliação da qualidade do biodiesel foram separados em quatro grupos conforme as informações que podem prover, sendo estes: métodos analíticos para determinação de contaminantes provenientes da matéria prima; métodos analíticos para avaliação do processo produtivo; métodos analíticos para avaliação das propriedades inerentes às estruturas moleculares; métodos analíticos para monitoramento da qualidade do biodiesel durante o processo de estocagem

A partir dos métodos analíticos aplicados na avaliação da qualidade do biodiesel podem-se obter informações importantes a respeito da seleção da matéria prima, do processo fabril e do armazenamento, bem como do desempenho do biodiesel como combustível e da qualidade das suas emissões.

\section{Métodos analíticos para determinação de contaminantes provenientes da matéria prima}

\section{Teor de fósforo e enxofre}

O conteúdo de fósforo no biodiesel é proveniente dos fosfolipídios encontrados tanto nos óleos vegetais como na gordura animal. Antes do processo de produção do biodiesel, o óleo ou gordura deverá passar por um pré-tratamento denominado degomagem, ${ }^{13}$ para remoção de grande parte dos fosfolipídios. Neste procedimento são removidas também outras impurezas como ceras, substâncias coloidais e íons metálicos, através da lavagem do óleo aquecido com água. A transesterificação de óleo vegetais brutos, ou seja, sem o tratamento prévio de degomagem, resultará na redução do rendimento da reação, ${ }^{14}$ bem como na produção de um biodiesel com alto teor de fósforo. Como consequência, as emissões irão conter grande quantidade de materiais particulados que poderão influenciar na operação de conversores catalíticos automotivos. ${ }^{15} \mathrm{O}$ fósforo é determinado no biodiesel via espectroscopia de emissão atômica com plasma indutivamente acoplado (ICP OES). Tanto a norma européia (EN 14214) como a brasileira (RANP 07/08) recomendam o método analítico EN ISO 14107. A norma brasileira recomenda ainda os métodos NBR 15553 e ASTM D4951. Este último é também indicado na norma americana ASTM D6751. O valor máximo de fósforo no biodiesel aceito nas três normas é de $10 \mathrm{mg} \mathrm{kg}^{-1}$.

Assim como o fósforo, o enxofre também é um típico veneno de catalisadores e, portanto, afeta os conversores catalíticos. A presença de enxofre no diesel mineral também está associada à emissão de material particulado, danos à saúde ${ }^{16}$ e à corrosão de partes do motor, atribuída aos ácidos sulfúrico e sulfônicos formados durante a oxidação do combustível. ${ }^{17} \mathrm{O}$ diesel com baixo teor de enxofre apresenta perda de lubricidade devido à remoção de compostos de nitrogênio e de oxigênio durante o processo do dessulfurização. ${ }^{18} \mathrm{O}$ biodiesel, no entanto, possui quantidades muito baixas de enxofre e excelente lubricidade, portanto pode atuar como aditivo para correção da lubricidade do diesel mineral. A norma EN 14214 estabelece o valor máximo de enxofre no biodiesel em $10 \mathrm{mg} \mathrm{kg}^{-1}$, com determinação através espectrometria de fluorescência molecular (método EN ISO 20846) ou através de fluorescência de raios-X dispersivo em comprimento de onda (método ISO 20884). A norma ASTM D6751 estabelece através do método D5453, por fluorescência molecular, o valor de máximo de $0,05 \%$ massa . A RANP 07/08 limita a quantidade de enxofre em $50 \mathrm{mg} \mathrm{kg}^{-1}$, podendo ser determinado por quaisquer dos métodos descritos acima. 
Tabela 1. Padrões de qualidade do biodiesel

CARACTERÍSTICA

\section{UNIDADE}

Aspecto

Massa específica *

Viscosidade cinemática a $40{ }^{\circ} \mathrm{C} *$

Água e sedimentos, máx. *

Ponto de fulgor, mín. *

Destilação; 90\% vol. recuperados, máx. *

Resíduo de carbono dos, máx. *

Cinzas sulfatadas, máx. *

Enxofre total, máx. *

Corrosividade ao cobre, $3 \mathrm{~h}$ a $50{ }^{\circ} \mathrm{C}$, máx. *

Número de cetanos *

Ponto de entupimento de filtro a frio, máx. *

Ponto de fluidez (pour point - PP) *

Ponto de nuvem (cloud point - CP) *

Sódio + Potássio, máx

Cálcio + Magnésio, máx

Fósforo, máx

Contaminação total, máx

Teor de éster, min.

Índice de acidez, máx.

Glicerina livre, máx.

Glicerina total, máx.

Monoglicerídeos

Diglicerídeos

Triglicerídeos

Metanol ou Etanol, máx.

Índice de iodo

Estabilidade à oxidação a $110^{\circ} \mathrm{C}$, mín

Água, máx

Ácido linolênico

Metil ésteres com mais que 4 insaturações

Límpido e isento de
---

$\begin{array}{cc}\mathrm{kg} / \mathrm{m} 3 & 850-900 \text { a } 20{ }^{\circ} \mathrm{C} \\ \mathrm{mm}^{2} / \mathrm{s} & 3,0-6,0 \\ \% \text { volume } & --- \\ { }^{\circ} \mathrm{C} & 100 \\ { }^{\circ} \mathrm{C} & ---\end{array}$

Em 100\% da amostra

$\%$ massa

0,050

0,020

$\%$ massa

$\mathrm{mg} / \mathrm{kg}$

50

1

Anotar

${ }^{\circ} \mathrm{C}$

${ }^{\circ} \mathrm{C}$

${ }^{\circ} \mathrm{C}$

$\mathrm{mg} / \mathrm{kg}$

$\mathrm{mg} / \mathrm{kg}$

$\mathrm{mg} / \mathrm{kg}$

$\mathrm{mg} / \mathrm{kg}$

$\%$ massa

mg KOH/g

$\%$ massa

$\%$ massa

$\%$ massa

$\%$ massa

$\%$ massa

$\%$ massa

$\mathrm{g} \mathrm{I}_{2} / 100 \mathrm{~g}$

$\mathrm{h}$

$\mathrm{mg} / \mathrm{kg}$

$\%$ massa

\%mass

Anotar

Anotar

Anotar

Anotar
UE

EN 14214

EUA

ASTM D6751 $--$

,9-6,0

0,05

130

360

$10 \%$ residual da destilação

0,3

0,02

10

15

1

3

51 (mín.)

47 (mín.)

Por região

Por região

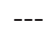

5

5

10

24

96,5

0,50

0,02

0,25

0,25

0,8 (máx)

0,2 (máx)

0,2 (máx)

0,20

0,20

120 (máx)

\section{6}

6

500

500

$12 \max$

Registrar

10

0,5

0,02

0,24

$---$

$--$

$---$

---

$---$

$---$

500

$---$

$1 \max$

* Parâmetros típicos da normatização do diesel mineral 


\section{Corrosividade ao cobre}

O ensaio de corrosividade ao cobre é um parâmetro estabelecido para determinar a capacidade potencial do combustível causar corrosão em peças metálicas, que podem ser do motor ou do tanque de armazenamento. Está propriedade está associada à presença de ácidos ou de compostos de enxofre. A necessidade deste parâmetro tem sido discutida, visto que já existe um método para determinação de acidez e no biodiesel o teor de enxofre é muito baixo. Neste ensaio de corrosividade uma lâmina de cobre previamente polida é submersa no combustível a $50{ }^{\circ} \mathrm{C}$, durante $3 \mathrm{~h}$. Em seguida, a placa é lavada e comparada com laminas padrões que representam diferentes graus de corrosão, aos quais são atribuídos valores de 1 a 5. Na norma ASTM o método recomendado é o D130, enquanto que na norma EN 14214 o método é o ISO 2160. Na RANP 07/08, além desses métodos, é estabelecido também o método ABNT NBR 14359. Os valores máximos aceitáveis são grau 1 de corrosão, tanto na norma EN 14214 quanto na RANP 07/08, e grau 3 para a Norma ASTM D6751.

\section{Cálcio e magnésio}

$\mathrm{O}$ valor máximo para a soma das concentrações de cálcio e magnésio é de $5 \mathrm{mg} \mathrm{kg}^{-1}$, estabelecido na RANP 07/08 e na norma EN 14214. O método analítico indicado por esses dois padrões de qualidade é o EN 14538, onde os metais são determinados por espectrometria de emissão atômica com plasma indutivamente aclopado (ICP OES), cujos comprimentos de onda indicados são 422,673 nm para o cálcio e 279,553 nm para o magnésio. Outros comprimentos de onda podem ser utilizados desde que estejam livres das interferências. Esse parâmetro não está presente na norma ASTM D6751.

Em 2002, Edlund e colaboradores estudaram o efeito da adição de oxigênio ao argônio para determinação multielementar simultânea de $\mathrm{Ca}, \mathrm{Cl}, \mathrm{K}, \mathrm{Mg}$, $\mathrm{Na}$ e $\mathrm{P}$ em biodiesel, por espectrometria de emissão com plasma indutivamente aclopado (ICP OES). ${ }^{19}$ Foi utilizado neste trabalho um espectrômetro ótico com detectores CCD e visão radial do plasma. Segundo os autores, as melhores relações sinal/ruído foram obtidas para o Na e o K quando empregada a mistura oxigênio/argônio, numa vazão de 0,35 e $0,8 \mathrm{~L} \mathrm{~min}^{-1}$, respectivamente. Este efeito foi atribuído à supressão do background proveniente da emissão dos compostos de carbono. Para este trabalho, a amostra foi diluída com querosene na proporção 1:4.

Empregando a mesma estratégia de adicionar oxigênio ao argônio, dos Santos e colaboradores realizaram determinações simultâneas de $\mathrm{Ca}, \mathrm{P}, \mathrm{Mg}, \mathrm{K}$ e Na em biodiesel por ICP OES, utilizando etanol para dissolução das amostras e ítrio como padrão interno. ${ }^{20}$ Neste trabalho, foram avaliadas através de otimização multivariada as influências do fluxo de $\mathrm{O}_{2}$, a rádio frequência do plasma, o fluxo do gás auxiliar e a pressão do nebulizador.

\section{Métodos analíticos para avaliação do processo produtivo}

\section{Aspecto}

O aspecto do biodiesel é um parâmetro considerado apenas na RANP 07/08. Trata-se de uma análise preliminar, onde se procura verificar a presença de impurezas que possam ser identificadas visualmente, como materiais em suspensão, sedimentos ou mesmo turvação na amostra de biodiesel, que pode ser decorrente da presença de água. Na ausência destes contaminantes, o biodiesel é classificado como límpido e isento de impurezas. $\mathrm{O}$ aspecto do biodiesel pode estar também relacionado com características moleculares do biodiesel, bem como com o processo de degradação durante a estocagem, conforme será descrito a seguir.

\section{Contaminação total}

A massa dos resíduos insolúveis retidos na filtração do biodiesel é utilizada no cálculo do valor do parâmetro denominado contaminação total. A norma ASTM não adotou esse parâmetro, que é recomendado na norma EN 14214 e na RANP 07/08, as quais utilizam o mesmo método analítico, ISO 12662. Ambas as normas adotaram o limite máximo $24 \mathrm{mg} \mathrm{kg}^{-1}$ para os resíduos retidos.

\section{Glicerina livre e total}

A glicerina é um co-produto da reação de transesterificação de óleos e gorduras. A determinação da glicerina residual serve como parâmetro para avaliar a eficiência do processo de purificação do biodiesel. Altas concentrações de glicerina no biodiesel provocam problemas de armazenamento, pois quando o biodiesel é misturado com o diesel de petróleo, observa-se a separação da glicerina nos tanques de estocagem. Problemas como formação de depósitos, entupimento dos bicos injetores do motor e emissões de aldeídos também estão relacionados com a alta concentração da glicerina no biodiesel.

A glicerina livre residual pode ser facilmente eliminada através de lavagens do biodiesel. Embora seja praticamente insolúvel no biodiesel, a glicerina pode ser encontrada dispersa na forma de gotículas. A presença de sabões residuais pode interferir, aumentando a concentração de glicerina no biodiesel devido à formação de emulsões. ${ }^{8}$ Tanto no Brasil, quanto na Europa e nos Estados Unidos, o teor máximo permitido de glicerina livre no biodiesel é de $0,02 \%$ e a sua determinação é realizada através dos métodos cromatográficos EN ISO 14105 e EN ISO 14106, estabelecidos pela norma européia, e o método ASTM D6584, pela norma americana. Esses métodos de análise também foram adotados pela norma brasileira, havendo ressalva quanto à necessidade de validação para biodieseis de matérias primas não previstas nos métodos e proveniente da rota etílica. Para biodieseis de misturas de matérias primas distintas, onde faça parte o óleo de mamona, a RANP 07/08 recomenda o método ABNT NBR 15341.

A glicerina combinada, que inclui mono-, di- e triglicerídeos, é proveniente da reação incompleta dos glicerídeos, logo, este é um importante parâmetro que pode ser utilizado para avaliar a eficiência da conversão de óleos e gorduras em biodiesel. A glicerina combinada pode ser calculada a partir das concentrações de mono-, di- e triglicerídeos, aplicando-se fatores de conversões individuais baseados na massa molar média dos ácidos graxos que participam da composição da matéria prima. ${ }^{21}$ Dependendo da concentração em que podem estar presentes no biodiesel, os glicerídeos não reagidos podem aumentar a viscosidade do combustível e, consequentemente, reduzir a eficiência da combustão, provocando entupimento do filtro de combustível e formação de depósitos em partes do motor como pistões, válvulas e bicos injetores. ${ }^{22}$ A soma da concentração da glicerina livre com a glicerina combinada é denominada como glicerina total. Quanto ao teor de glicerina total, a norma brasileira e a européia estabelecem um limite máximo de $0,25 \%$ massa , enquanto nos Estados Unidos o limite é de $0,24 \%$

Atualmente a cromatografia a gás em altas temperaturas (High temperature gas chromatography - HTGC) é a técnica cromatográfica mais amplamente utilizada para análise de glicerina livre e total em biodiesel. Os métodos analíticos americano e europeu foram desenvolvidos para análise de glicerina livre e total, tendo como base biodieseis metílicos de soja (ASTM D6584), canola e girassol (EN ISO 14105), respectivamente. No mundo, todo biodiesel produzido em escala comercial é proveniente da rota metílica e, em maior parte, originário da soja ou canola. No Brasil, existe uma grande variedade de matérias primas que podem ser utilizadas na produção do biodiesel, além do uso da rota etanólica que pode ser implementada. Neste caso, torna-se premente a validação dos métodos analíticos ou o desenvolvimento de novos métodos de determinação de glicerina livre e total para biodieseis de diferentes matérias primas e rotas de transesterificação. Tanto a norma 
européia como a americana utilizam a HTGC para determinação de glicerina livre e glicerídeos não reagidos em biodiesel. Muito pouca variação é observada entre os métodos empregados (Tabela 2). Esses métodos são recomendados pela norma brasileira para análise de biodiesel. Quanto à análise de glicerina total em biodieseis de misturas de matérias primas distintas, onde faça parte o óleo de mamona, a RANP 07/08 recomenda o método ABNT NBR 15344.

Durante o período de 1984 a 2006, vários métodos cromatográficos foram propostos para análise de biodiesel (Tabela 3). Nesta ocasião foram realizadas comparações entre técnicas cromatográficas, uso de derivatizantes e entre sistemas de detecção. As técnicas cromatográficas trabalhadas foram a cromatografia em camada delgada com detecção por ionização de chama (TLC/FID - Thin-layer chromatography with Flame-Ionization Detection), cromatografia a gás em altas temperaturas (HTGC/FID - High temperature gas chromatography with flame-ionization detection), cromatografia por exclusão molecular (SEC - Size-Exclusion Chromatography) e a cromatografia líquida de alta eficiência (HPLC - High Performance Liquid Chromatography). Essa última foi empregada com diferentes formas de detecção: por espectrometria de massa por ionização química à pressão atmosférica (HPLC/API-MS - High Performance Liquid Chromatography with atmospheric pressure chemical ionization mass spectrometry detection); por ultravioleta (High Performance Liquid Chromatography with ultraviolet detection); por espalhamento de luz por evaporação (HPLC/ ELSD - High Performance Liquid Chromatography with evaporative light scattering detection).

Tabela 2. HTGC: comparação entre o método europeu e o americano

\begin{tabular}{|c|c|c|}
\hline & $\begin{array}{c}\text { Norma Européia - EM } 14214 \\
\text { (método EM 14105) }\end{array}$ & $\begin{array}{c}\text { Norma Americana - ASTM D } 6751 \\
\text { (método D 6584) }\end{array}$ \\
\hline Coluna capilar & $\begin{array}{l}\text { 100\% dimetilpolissiloxano ou } \\
5 \% \text { difenilpolissiloxano } \\
\text { Comprimento de } 10 \mathrm{~m} \\
\text { Diâmetro interno de } 0,32 \mathrm{~mm} \\
0,1 \mathrm{~mm} \text { de espessura do filme }\end{array}$ & $\begin{array}{l}5 \% \text { fenil-polidimetilsiloxano } \\
\text { Comprimento de } 10 \text { ou } 15 \mathrm{~m} \\
\text { Diâmetro interno de } 0,32 \mathrm{~mm} \\
0,1 \mathrm{~mm} \text { de espessura do filme }\end{array}$ \\
\hline Temperatura do forno & Inicial $50^{\circ} \mathrm{C} /$ Final $370^{\circ} \mathrm{C}$ & Inicial $50^{\circ} \mathrm{C} /$ Final $380^{\circ} \mathrm{C}$ \\
\hline Injetor & On column & On column \\
\hline
\end{tabular}

Tabela 3. Métodos cromatográficos para análise de biodiesel

Técnica

Comentários

Ref.

TLC/FID

Foi o primeiro método cromatográfico para análise de biodiesel. Determinação de metil ésteres, mono-, di- e triglicerídeos. Baixa precisão, sensibilidade à umidade e custo alto do equipamento.

HTGC/FID

Análise de ésteres, mono-, di- e triglicerídeos, na mesma corrida, para estudo da reação de transesterificação de óleos soja. Separação do éster e dos mono-, di- e triglicerídeos, em 12 min.

HPLC

Avaliação da taxa de conversão numa reação de transesterificação metílica. Determinados ésters metílicos, mono-, di- e triglicerídeos.

GC/MS

GC/FID

Avaliação dos sistemas de detecção FID e MS para análise de glicerina livre. Elevados percentuais de recuperação do analito e limites de detecção da ordem de $10^{-5} \%$ para MS e $10^{-4} \%$ para FID. Detecção MS evita a sobreposição de picos, permitindo o uso de colunas mais curtas.

Quantificação de glicerina livre, mono-, di- e triglicerídeos em biodiesel, numa mesma corrida cromatográ-

HTGC/FID fica. Constatou a maior eficiência do MSTFA como derivatizante quando comparado ao BSTFA. Calibração externa com soluções padrões de glicerina, mono-, di- e trioleina. Base do método ASTM D6584

Determinados ésters metílicos, mono-, di- e triglicerídeos. Comparação entre 3 diferentes sistemas de

HPLC/UV

HPLC/ELSD

HTGC

HPLC detecção: API-MS, UV em 205 nm, ELSD. UV não quantificou os compostos saturados. API-MS e ELSD apresentaram decréscimo na sensibilidade com incremento das ligações duplas nos alquilésteres. Detecção por API-MS mostrou-se mais adequada para análise de óleo de colza e biodiesel.

Comparação entre as técnicas. Não encontraram diferença estatisticamente significante entre os resultados obtidos. Produtos de oxidação do biodiesel são detectados por HPLC, mais não por HTGC.

SEC

Numa mesma corrida cromatográfica (36 min) foram quantificados, os teores de mono-, di- e triglicerídeos, além de dos ésteres metílicos, ácidos graxos, glicerina livre e metanol em biodiesel de girassol.

Propôs o uso de injeção split pulsado para análise de álcool, glicerina livre, ésteres, mono-, di- e triglicerídeos utilizando uma única condição cromatográfica.

HTGC

Método desenvolvido para monitoramento de ésteres, mono-, di- e triglicerídeos durante a transesterifiação 
Flogia e colaboradores, em 2004, compararam o uso da HPLC e da HTGC na análise de glicerídeos em biodiesel. ${ }^{29}$ Segundo os autores, não foram encontradas diferenças estatisticamente significativas entre os resultados obtidos. Exceções foram encontradas quando estavam presentes produtos de oxidação do biodiesel detectados por HPLC, mas não por HTGC, pois são eluídos juntamente com os diglicerídeos. Os autores apontaram algumas desvantagens quanto ao emprego da cromatografia a gás (GC) para análise de glicerídeos em biodiesel, tais como a necessidade de derivatização (tornando a GC mais limitada no monitoramento do processo de transesterificação), uso de padrões internos de glicerídeos, não especiação de alquilésteres e de glicerídeos residuais, uso de diferentes padrões em função da matéria prima empregada na produção de biodiesel, limitação na determinação dos alquilésteres.

A cromatografia em fase líquida de alta eficiência é apontada como alternativa por apresentar vantagens como: não necessita de derivatização, menor tempo de análise e pronta quantificação de alquilésteres, ácidos graxos livres, triglicerídeos, 1,2- e 1,3-diglicerídeos, 1- e 2-monoglicerídeos, o que permite seu emprego no monitoramento da reação de transesterificação. Por outro lado, o número grande de informações obtidas através da HPLC pode ser interpretado como desvantagem, tendo em vista o grande número de compostos existentes no biodiesel. ${ }^{33}$ Uma outra desvantagem da HPLC é a impossibilidade de se determinar na mesma corrida a glicerina livre.

Métodos analíticos não cromatográficos também foram propostos para análise de glicerina livre e total. Uma estratégia empregada é a oxidação da glicerina livre com ácido periódico, resultando em ácido fórmico e aldeído fórmico. A concentração de glicerina livre é calculada com base no resultado da titulação do ácido fórmico, obedecendo à estequiometria da reação de oxidação. Segundo Mittelbach,,$^{21}$ este método não possui sensibilidade suficiente para quantificação da glicerina livre em biodiesel.

A glicerina total pode ser quantificada por iodometria. ${ }^{34}$ Neste caso, uma amostra do biodiesel é previamente saponificada para liberação de toda a glicerina que se encontrava na forma de glicerídeos, em seguida, o meio é acidificado para neutralização completa dos sabões. A glicerina extraída na fase aquosa é, então, oxidada com excesso de ácido periódico. O ácido periódico remanescente é, então, titulado com uma solução padrão de tiossulfato de sódio.

A oxidação da glicerina com ácido periódico oferece também a possibilidade de quantificação por espectrofotometria, reagindo-se o aldeído formado com uma determinada substância, de forma a se obter um composto que absorva energia eletromagnética na região do visível. O ácido cromotrópico pode então ser empregado para este fim, fazendo-o reagir com o aldeído gerado, em meio de ácido sulfúrico concentrado e sob aquecimento, dando origem a um complexo que absorve em $580 \mathrm{~nm} .{ }^{35} \mathrm{Em}$ 1996, Lozano e colaboradores fizeram uso do ácido cromotrópico para quantificação da glicerina livre em biodiesel. ${ }^{36} \mathrm{O}$ limite de detecção alcançado foi de $1 \mu \mathrm{g} \mathrm{g}^{-1}$, utilizando-se quantificação via HPLC, com detecção amperométrica pulsada.

A acetilacetona também foi estudada como reagente de cor para reação com o formaldeído. Alguns métodos analíticos utilizando-se a acetilacetona foram empregados para a quantificação de triglicerídeos por espectrofotometria em soro humano, após a liberação da glicerina por transesterificação e sua posterior oxidação, gerando assim o formaldeído. ${ }^{37}$ Baseando-se neste raciocínio, Bondioli e Bella propuseram um método espectrofotométrico para quantificação da glicerina livre em biodiesel. ${ }^{8} \mathrm{O}$ princípio do método é a reação do formaldeído, originado da oxidação da glicerina com o ácido periódico, com a acetilacetona segundo a reação de Hantzsch. O composto formado é 3,5-diacetil-1,4-di-hidrolutidina, que absorve a $410 \mathrm{~nm}$. Conforme os testes aplicados, os autores constataram a aplicabilidade do método tanto para a quantificação de glicerina livre como também na mistura diesel/biodiesel.
Os métodos espectrofotométricos de quantificação da glicerina livre ou total em biodiesel, baseados na oxidação da glicerina e quantificação indireta através do formaldeído gerado, foram propostos como alternativa aos métodos cromatográficos, por serem muito mais rápidos na etapa de quantificação e apresentarem custos mais baixos que os métodos cromatográficos. No entanto, os métodos espectrofotométricos apresentados são muito mais laboriosos na etapa de preparação da amostra, que pode consistir de uma fase de transesterificação ou saponificação para liberar a glicerina combinada (no caso da determinação da glicerina total), uma fase de extração da glicerina e, por fim, a oxidação com ácido periódico.

Uma proposta de análise qualitativa dos intermediários da reação de transesterificação de óleos e gorduras foi apresentada por Catharino e colaboradores.$^{38} \mathrm{Em}$ seu trabalho, foi possível identificar a presença de mono-, di- e triglicerídeos em biodiesel de diferentes origens empregando espectrometria de massa com ionização por eletrospray (Eletrospray Ionisation Mass Spectrometry - ESI-MS). Além dos intermediários da reação, foi possível também identificar produtos de oxidação do biodiesel, o álcool do qual os ésteres provieram, glicerol e sais de sódio. A caracterização dos ácidos graxos constituintes dos óleos percussores também foi realizada, sendo possível desta forma identificar a oleaginosa de origem do biodiesel.

\section{Resíduo de carbono}

A tendência de formação de depósitos nas câmaras de combustão pode ser avaliada através da determinação dos resíduos de carbono. Além dos sabões e dos glicerídeos residuais, contribuem para os valores de resíduo de carbono a água livre, os ácidos graxos livres, o resíduo de catalisadores e os insaponificáveis oriundos da matéria prima. Neste ensaio, a amostra é evaporada e queimada e o resíduo final é pesado. O método de análise adotado pelas normas brasileira e americana é o ASTM D4530, onde o ensaio é realizado em 100\% da amostra. No método EN ISO 10370 da norma européia, a análise é realizada nos $10 \%$ remanescentes da destilação, que é uma estratégia que pode ser empregada quando os resultados são inferiores a $0,10 \%$. O limite máximo para este parâmetro é de $0,050 \%_{\text {massa }}$ para a norma

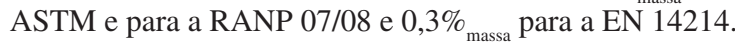

\section{Teor de éster}

$\mathrm{O}$ teor de ésteres metílicos no biodiesel é um parâmetro previsto na norma EN 14214 e na RANP 07/08, cuja porcentagem mínima exigida de éster é de $96,5 \%$ massa , a ser determinada através do método cromatográfico EN ISO 14103. A massa do éster é obtida através da comparação da área total dos picos correspondentes com a área do pico heptadecanoato de metila, utilizado como referência. A norma européia estabelece ainda o controle da concentração de ésteres poliinsaturados no biodiesel, devido a sua propensão à oxidação, fixando um valor máximo de $12 \%_{\text {massa }}$ para o linolenato de metila e $1 \%_{\text {ma }}$ para ésteres metílicos com mais de três insaturações. Neste caso, o mesmo método EN 14103 é empregado e o teor do éster é calculado através da razão entre a área do pico do éster em questão pela área do pico da substância de referência. ${ }^{39}$ A norma brasileira recomenda ainda o uso do método ABNT NBR 15342, a ser empregado na análise de biodieseis oriundos de gordura animal ou de misturas de matérias primas distintas, das quais faça parte o óleo de mamona.

A quantificação de ésteres em biodiesel por HPLC também tem sido estudada, objetivando inclusive o seu emprego no monitoramento do processo produtivo. ${ }^{25,29} \mathrm{O}$ teor de ésteres também pode ser monitorado durante a reação de transesterificação por ressonância nuclear magnética protônica (proton nuclear magnetic resonance - ${ }^{1} \mathrm{H}-\mathrm{NMR}$ ). O primeiro trabalho proposto neste sentido foi publicado por Gelbard e colaboradores, ${ }^{40}$ onde o cálculo da taxa de conversão em metil ésteres se baseia na razão entre a área do singlete dos prótons da metila, 
diretamente ligada à carboxila do metil éster $\left(\mathrm{CH}_{3} \mathrm{OCO}-\right)$, e a área dos sinais dos seus prótons metilênicos $\alpha$-carbonílicos $\left(-\mathrm{OCOCH}_{2}-\right)$. O resultado é, por fim, multiplicado pelo fator $2 / 3$, que corresponde à quantidade de átomos de hidrogênios presentes na molécula dos ésteres metílicos envolvidos no cálculo, ou seja, há dois hidrogênios -carbonílicos e três hidrogênios metoxílicos. Desta forma pretende-se igualar a área dos sinais dos prótons envolvidos.

A quantificação de éteres etílicos utilizando ${ }^{1} \mathrm{H}$ RMN também foi estudada em 2004 por Neto e colaboradores. ${ }^{41}$ Os autores utilizaram um espectrômetro de baixa frequência (200 MHz) e reportaram a sobreposição parcial dos sinais dos prótons do carbono etílico do éster, que se encontra diretamente ligado à carboxila, com os sinais dos prótons metilênicos da porção alcoxi dos trilicerídeos, todos compreendidos na região de 4,05 a 4,40 ppm. Em vista do observado, foi proposta uma estratégia diferente da relatada por Gelbard e colaboradores ${ }^{39}$ para quantificação de ésteres metílicos. Neste caso, foi empregada como resposta analítica a razão entre a área do sinal dos prótons metilênicos da porção glicerol do triglicerídeo e a área do quarteto gerado pelos prótons $\mathrm{CH}_{2}$ etoxílico do etiléster. Os resultados foram comparados com medidas de viscosidade, obtendo-se um coeficiente de correlação linear de 0,9981 .

Garcia $^{42}$ propôs o uso do pico na região entre 4,07-4,09 do espectro ${ }^{1} \mathrm{H}$ RMN, que compõe o quarteto gerado pelos prótons $\mathrm{CH}_{2}$ etoxílico do etiléster, para o cálculo da porcentagem de ésteres etílicos. Como este sinal tem 1/8 da área total do quarteto e é o único pico de ressonância do éster étílico que não apresenta sobreposição com nenhum outro sinal dos mono-, di-, ou triglicerídedos, compreendidos entre 4,05 e 4,35, o cálculo da percentagem do éster pode ser realizado através da equação \% $\mathrm{EE}=\left[\left(\mathrm{A}_{c 4} \times 8\right) / \mathrm{A}_{\mathrm{T}}\right] \times 100$; onde: \% EE é a porcentagem de ésteres etílicos; $\mathrm{A}_{c 4}$ é a área do pico do quarteto em 4,07-4,09 ppm, correspondente aos prótons $\mathrm{CH}_{2}$ etoxílico do etiléster e $\mathrm{A}_{\mathrm{T}}$ é a área de todos os sinais entre 4,35 e 4,05 ppm. Para biodieseis metílicos, o cálculo do percentual de ésteres é realizado seguindo o mesmo raciocínio, fazendo-se a relação entre a área do singlete inerente aos prótons metoxílicos e a área total na região entre 4,35 e 4,10 ppm.

Análises baseada em ${ }^{1} \mathrm{H}$ RMN também foram realizadas para estudo da cinética da reação de transesterificação $0^{43}$ e para identificação dos intermediários produzidos durante a reação. ${ }^{33}$ A quantificação de ésteres em biodiesel por ${ }^{1} \mathrm{H}$ RMN tem sido classificada como mais rápida e mais simples do que quando realizada por HTGC ou HPLC, no entanto deve-se levar em consideração o custo do equipamento e de sua manutenção. ${ }^{44}$

\section{Ponto de fulgor}

O ponto de fulgor é a temperatura mínima onde é observada a liberação de vapores de um líquido, em quantidade suficiente para forma uma mistura inflamável com o ar. Para o biodiesel, os valores de ponto de fulgor são, consideravelmente, mais elevados que os valores encontrados para o diesel mineral. Para o biodiesel puro o valor do ponto de fulgor encontra-se próximo aos $170^{\circ} \mathrm{C}$, porém, mínimas quantidades de álcool adicionadas ao biodiesel ocasionam um decréscimo bastante significativo neste valor. ${ }^{45}$ Este comportamento torna o ponto de fulgor um parâmetro muito importante quanto à segurança no armazenamento e no transporte, principalmente quando a transesterificação foi realizada com metanol que, além de altamente inflamável, apresenta elevada toxidez. Quanto aos valores de ponto de fulgor permitidos para o biodiesel, a norma ASTM D6751 (método analítico ASTM D93) é a mais restritiva dos três parâmetros de qualidade de biodiesel que estão sendo analisados, fixando um valor mínimo de $130{ }^{\circ} \mathrm{C}$, enquanto a norma EN 14214 (método analítico EN ISO 3679) estabelece o valor de $120^{\circ} \mathrm{C}$ e a RANP $07 / 08$ o valor de $100{ }^{\circ} \mathrm{C}$. A RANP 07/08 recomenda, além dos métodos citados, o método ABNT NBR 14598.

\section{Metanol e etanol}

O teor de álcool no biodiesel pode ser utilizado também para avaliar o processo de purificação do biodiesel. A concentração de álcool é determinada pelo método cromatográfico EN ISO 14110, indicado pela norma EN 14214, para determinação de metanol no biodiesel, e pela RANP 07/08, para determinação tanto de metanol como de etanol. Na análise, é empregado um cromatógrafo equipado com uma coluna capilar polar, utilizando um detector de ionização de chama. Uma fração da fase gasosa de um recipiente hermeticamente fechado, contendo a mostra em equilíbrio a $80{ }^{\circ} \mathrm{C}$, deverá então ser injetada no cromatógrafo, utilizando-se 2-propanol para calibração interna. A norma brasileira indica também o método ABNT NBR 15343, principalmente para análise de biodieseis de misturas de matérias primas onde uma delas é o óleo de mamona. Na norma EN 14214 é estabelecido o limite máximo de metanol de $0,20 \%{ }_{\text {massa }}$. Na RANP 07/08, tanto o teor de metanol como de etanol é fixado em $0,20 \%$ massa , no entanto, a determinação de álcool é dispensada no caso de valores de ponto de fulgor superiores a $130{ }^{\circ} \mathrm{C}$.

Faria e colaboradores propuseram uma alteração para o método NBR 15343, aplicável na determinação de álcool (metanol ou etanol) em biodiesel. ${ }^{46}$ Dentre as alterações propostas, foi instalada no injetor do cromatógrafo uma válvula de reversão de fluxo, com a finalidade de impedir que os componentes mais pesados do biodiesel sejam introduzidos na coluna. Para tanto, o fluxo é revertido logo após a eluição do padrão interno terc-butanol. Com essa medida, o tempo de análise foi reduzido para menos de $10 \mathrm{~min}$

Como método alternativo, Paraschivescu e colaboradores apresentaram a determinação de metanol em biodiesel utilizando headspace com microextração em fase sólida (solid phase microextraction SPME).${ }^{47}$ Neste trabalho, foi empregada fibra de polidimetilsiloxano para extração e pré-concentração do metanol da amostra em frasco hermeticamente fechado e a $50^{\circ} \mathrm{C}$, sob agitação constante. $\mathrm{O}$ metanol foi injetado no cromatógrafo a gás por dessorção a $200{ }^{\circ} \mathrm{C}$ durante 2 min. Conforme os resultados e comparações com o método EN ISO 14110, o método proposto mostrou-se reprodutível, com sensibilidade e faixa analítica maiores que o método padrão, sem necessidade de padronização interna.

\section{Cinzas sulfatadas}

A concentração de contaminantes inorgânicos no biodiesel pode ser avaliada com base no teor de cinzas sulfatadas. O método baseiase na queima da amostra na presença de ácido sulfúrico, a fim de converter as impurezas metálicas em seus sulfatos correspondentes, reduzindo a perda de material por volatilização. Os óxidos de sódio e de potássio, por exemplo, são mais voláteis que os seus sulfatos. Aplica-se este método para determinação de catalisador residual em biodiesel ( $\mathrm{Na}$ e K), porém outros elementos podem estar presentes, como é o caso do fósforo que é proveniente do óleo não degomado. ${ }^{21}$ A presença de catalisador residual no biodiesel pode acarretar danos por abrasão às peças do motor. O teor máximo de cinzas sulfatadas em biodiesel é de $0,020 \%$ massa estabelecido pela norma EN 14214 (método analítico EN ISO 3987) e pela RANP 07/08 (métodos analíticos ABNT NBR 6294, ASTM D874 e EN ISO 3987). A norma ASTM D6751 não prevê este método como parâmetro de qualidade para o biodiesel.

\section{Sódio e potássio}

A determinação de sódio e potássio em biodiesel também está prevista por espectrometria de absorção atômica. A norma EN 14214 e a RANP 07/08 utilizam o método EN ISO 14108 para o sódio, cuja leitura é realizada a $589 \mathrm{~nm}$, e EN ISO 14109 para o potássio, a 766,5 $\mathrm{nm}$. A norma brasileira também prevê para esse ensaio a aplicação dos métodos ABNT NBR de números 15553, 15554, 15555 e 15556. 
A norma ASTM D6751 emprega o método analítico UOP 391. O teor máximo permitido nesses padrões de qualidade para a soma das concentrações de sódio e potássio é de $5 \mathrm{mg} \mathrm{kg}^{-1}$.

Um método empregando a fotometria de chama foi proposto como uma alternativa simples e de baixo custo para determinação de sódio em biodiesel. ${ }^{48}$ Antes da realização das medidas, $0,5 \mathrm{~g}$ da amostras é tratada previamente por pirólise a $250^{\circ} \mathrm{C}$ por $1 \mathrm{~h}$ em forno mufla e a $600{ }^{\circ} \mathrm{C}$ por $4 \mathrm{~h}$; por fim, as cinzas obtidas são dissolvidas em ácido nítrico 1,0\%. Embora o método seja uma alternativa de menor custo analítico, apresenta uma etapa de preparo da amostra mais laboriosa e demorada.

O uso de microemulsão para determinação de sódio e potássio em biodiesel por espectrometria de absorção atômica com atomização de chama - FAAS, foi proposto por de Jesus e colaboradores. ${ }^{49}$ Microemulsões estáveis foram obtidas com mistura de $57,6 \%$ massa de npentanol, $20 \%$ da amostra de biodiesel ou óleo vegetal, 14,4\% Triton X-100 e $8 \%$ massa de água. Segundo os resultados apresentados, a microemulsão apresentou estabilidade muito maior que a solução do biodiesel em solvente orgânico, conforme é proposto nos métodos EN ISO 14108 e EN ISO 14109. Os limites de detecção e quantificação também foram melhores. O emprego de microemulsão possibilitou o uso de padrões inorgânicos.

Castilho e Stradiotto apresentaram um método potenciométrico para determinação de potássio em biodiesel, utilizando um eletrodo modificado com hexacianoferrato.$^{50}$ De acordo com os resultados, o eletrodo apresentou alta seletividade para o íon potássio, no entanto, sofreu interferência na presença de íons $\mathrm{NH}_{4}{ }^{+}$. A faixa de concentração onde foi obtida uma resposta linear para o potássio foi de $4.0 \times 10^{-5}$ a $1.0 \times 10^{-2} \mathrm{~mol} \mathrm{~L}^{-1}$ e um limite de detecção de $1,9 \times 10^{-5} \mathrm{~mol} \mathrm{~L}^{-1}$.

Outros métodos alternativos para determinação de sódio e potássio em biodiesel são apresentados adiante.

\section{Métodos analíticos para avaliação das propriedades inerentes às estruturas moleculares}

Algumas propriedades do biodiesel estão relacionadas com as estruturas moleculares dos seus alquil ésteres constituintes. ${ }^{51}$ Neste contexto, parâmetros analíticos foram adotados visando o controle deste feito sobre o desempenho do combustível. Dentre estes estão a massa específica, a viscosidade cinemática, o índice de iodo, fração de destilados, número de cetano, ponto de névoa, ponto de entupimento de filtro a frio e ponto de fluidez.

\section{Massa específica}

A densidade do biodiesel está diretamente ligada com a estrutura molecular das suas moléculas. Quanto maior o comprimento da cadeia carbônica do alquiléster, maior será a densidade, no entanto, este valor decrescerá quanto maior for o número de insaturações presentes na molécula. A presença de impurezas também poderá influenciar na densidade do biodiesel como, por exemplo, o álcool ou substâncias adulterantes.

Comparado com o diesel mineral, o biodiesel apresenta maior densidade. Dentre os padrões de qualidade apresentados, a norma ASTM não considera relevante a densidade do biodiesel como parâmetro de qualidade. Tanto para a resolução brasileira, como para a norma européia, os métodos de análise da densidade do biodiesel são os mesmos comumente aplicados aos derivados de petróleo. A norma européia estabelece valores de densidade entre 860 a 900 kg $\mathrm{m}^{-3}$, com determinação através dos métodos EN ISO 3675, que utiliza hidrômetros de vidro, e EN ISO 12185, que emprega densímetros digitais. A RANP 07/08, fixa uma faixa de valores de densidade entre 850 a $900 \mathrm{~kg} \mathrm{~m} 3$. Nesta resolução, além dos métodos indicados pela norma européia, são estabelecidos os métodos ASTM D1298 e NBR 7148 (hidrômetros de vidro) e os métodos ASTM D4052 e NBR 14065 (decímetros digitais). A resolução brasileira estabelece ainda que o biodiesel produzido tem um prazo máximo de um mês, a contar da data de certificação, para ser comercializado. Passado este prazo, deve ser realizada uma nova análise da massa específica a $20{ }^{\circ} \mathrm{C}$, onde, havendo diferença inferior a $3,0 \mathrm{~kg} / \mathrm{m}^{3}$ em relação ao valor do certificado, deverão ser novamente analisados o teor de água, o índice de acidez e a estabilidade à oxidação a $110^{\circ} \mathrm{C}$. Caso a diferença seja superior a $3,0 \mathrm{~kg} / \mathrm{m}^{3}$, deverão ser reavaliados todos os parâmetros de qualidade da resolução.

\section{Viscosidade cinemática a $40^{\circ} \mathrm{C}$}

A viscosidade do biodiesel aumenta com o comprimento da cadeia carbônica e com o grau de saturação ${ }^{12}$ e tem influência no processo de queima na câmara de combustão do motor. Alta viscosidade ocasiona heterogeneidade na combustão do biodiesel, devido à diminuição da eficiência de atomização na câmara de combustão, ocasionando a deposição de resíduos nas partes internas do motor.

Os sabões residuais, bem como os glicerídeos não reagidos (mono-, di- e triglicerídeos) e os produtos da degradação oxidativa do biodiesel, aumentam a viscosidade do biodiesel. Estes contaminantes podem, portanto, ser monitorados indiretamente através da determinação da viscosidade cinemática a $40^{\circ} \mathrm{C}$. A norma EN 14214 (método analítico EN ISO 3104) estabelece um intervalo aceitável de viscosidade de 3,5 a $5,0 \mathrm{~mm}^{2} / \mathrm{s}$, enquanto a norma ASTM D6751 (método analítico D 445) permite um intervalo pouco mais amplo, de 1,9 a $6,0 \mathrm{~mm}^{2} / \mathrm{s}$. A RANP 07/08, além dos métodos analíticos já citados, recomenda também o método ABNT NBR 10441. A faixa de viscosidade permitida pela RAP $07 / 08$ é de 3,0 a $6,0 \mathrm{~mm}^{2} / \mathrm{s}$.

\section{Índice de iodo}

O número de insaturações não tem apenas efeito nos valores de densidade e de viscosidade dos biodieseis, mas também é de grande importância na estabilidade oxidativa dos biodieseis como será explicado adiante. As normas EN 14214 e RANP 07/08 adotaram o índice de iodo (método analítico EN ISO 1411) para determinar o número de insaturações. O método baseia-se no tratamento da amostra com halogênios em excesso, que se adicionarão às duplas ligações. Os halogênios não reagidos são então titulados como tiossulfato de sódio e o resultado expresso como gramas de iodo que reagem com as insaturações em $100 \mathrm{~g}$ de amostra. O valor máximo aceito na norma EN 14214 é de $120 \mathrm{~g} \mathrm{I}_{2} / 100 \mathrm{~g}$. A RANP 07/08 solicita o registro do resultado da análise.

Reda e colaboradores mostraram que é possível calcular o índice de iodo e a massa molar média de biodieseis etílicos utilizando a espectroscopia de ressonância nuclear magnética. ${ }^{52} \mathrm{O}$ custo de aquisição e manutenção do equipamento torna-se um empecilho para esta aplicação da técnica.

\section{Destilação - $90 \%$ vol. recuperados}

A determinação da curva de destilação é um parâmetro de análise típico do diesel mineral e tem relações com propriedades como viscosidade, pressão de vapor e valor de aquecimento. Segundo Knothe, ${ }^{44}$ este parâmetro não tem aplicação para o biodiesel, pois os alquilésteres que o compõe não apresentam pontos de ebulição similares. Segundo Prankl, este parâmetro foi adicionado para avaliar a contaminação por materiais com alto ponto de ebulição, a exemplo de óleos usados de motor. ${ }^{46}$ Apenas a norma ASTM D6751 estabelece esse parâmetro como componente do padrão de qualidade, indicando o método analítico ASTM D1160, fixando a temperatura máxima de $360^{\circ} \mathrm{C}$ para a destilação dos $90 \%$ da amostra. Este ensaio deixou de fazer parte do padrão de qualidade brasileiro, a partir da RANP 07/08. 


\section{Número de cetanos}

Assim como a octanagem, o número de cetanos é indicativo do tempo de atraso na ignição de combustíveis para motores do ciclo diesel, logo, reflete a qualidade da ignição do combustível. Quanto maior o número de cetanos mais curto será o tempo de ignição. $\mathrm{O}$ número de cetanos aumenta com o comprimento da cadeia carbônica não ramificada, desta forma, o hexadecano (cetano) é estabelecido como padrão de valor de 100 na escala de cetano, enquanto que para o 2,2,4,4,6,8,8-heptametilnonano é atribuído o valor $15 .{ }^{12} \mathrm{O}$ teste de cetano é realizado em um motor de bancada de quatro tempos, com um único cilindro e ignição por compressão, projetado para testes de amostras de combustíveis para motores diesel.

Comparado com o diesel fóssil, o biodiesel apresenta maiores valores de número de cetanos. Na Europa, tanto para o diesel como para o biodiesel, o número de cetanos mínimo aceitável é fixado em 51 (método EN ISO 5165). No padrão de qualidade americano, o número de cetanos para o diesel é 40, enquanto que para o biodiesel é estabelecido em 47 (método D 613). Na norma brasileira não há um valor mínimo estabelecido de número de cetanos para o biodiesel, sendo solicitado o registro do valor medido.

Peres e colaboradores propuseram um modelo matemático para o cálculo do número de cetanos e do poder calorífico para diferentes tipos de biodieseis. ${ }^{53}$ Os modelos matemáticos foram elaborados confrontandose a composição dos biodieseis, em termos de ácidos graxos, obtidos por análise cromatográfica e os valores de número de cetanos e poder calorífico para os principais ácidos graxos descritos na literatura.

\section{Ponto de névoa, ponto de entupimento de filtro a frio e ponto de} fluidez.

A baixa temperatura, o biodiesel tende a solidificar-se parcialmente ou a perder sua fluidez, levando à interrupção do fluxo do combustível e entupimento do sistema de filtração, ocasionando problemas na partida do motor. A partir deste comportamento, foram elaborados três ensaios de laboratório: ponto de névoa (cloud point - $\mathrm{CP}$ ), que é a temperatura do combustível em um processo de resfriamento, onde se observa formação dos primeiros cristais (método ASTM D2500); ponto de entupimento de filtro a frio (cold-filter plugging point - CFPP), que é a temperatura em que o combustível perde a filtrabilidade quando resfriado (método EN ISO 116/método similar americano: LTFT - low temperature flow test - ASTM D 4539); ponto de fluidez (pour point - PP), que é a temperatura em que o combustível perde sua fluidez quando sujeito a resfriamento sob determinadas condições de teste (método EN ISO 3016).

Estas informações são de grande importância para avaliar a aplicabilidade do combustível em regiões de clima frio. Quanto maior for o tamanho da cadeia e/ou o caráter saturado das moléculas do biodiesel, mais alto serão os valores destes parâmetros. É de se esperar, portanto, que o biodiesel originário de gordura animal apresente valores mais elevados que o biodiesel proveniente de gordura vegetal, devido ao seu alto teor de ácidos graxos saturados. $\mathrm{Na}$ análise de um mesmo biodiesel, verifica-se que o CP, quando comparado com CFPP e PP, apresentará sempre os maiores valores de temperatura, podendo ser considerado como o mais restritivo. Nesta análise, o PP será então o menos restritivo.

Na Europa, os valores de CFPP e PP devem ser estabelecidos por cada país em função do seu clima. Nos Estados Unidos, o valor de $\mathrm{CP}$ é dependente da sazonalidade do clima. No Brasil, excetuando biodiesel puro de mamona, é estabelecida a determinação do ponto de entupimento de filtro a frio para o biodiesel, conforme os métodos ABNT NBR 14747, EN ISO 116 e ASTM D6371. O valor máximo de $19{ }^{\circ} \mathrm{C}$ estabelecido na Resolução brasileira é aplicável para as regiões Sul, Sudeste, Centro-Oeste e para o estado da Bahia, devendo ser anotado para as demais regiões.

\section{Métodos analíticos para monitoramento da qualidade do biodiesel durante o processo de estocagem}

\section{Estabilidade à oxidação a $110^{\circ} \mathrm{C}$}

A estabilidade oxidativa do biodiesel está diretamente relacionada com o grau de insaturação dos alquilésteres presentes, ${ }^{15}$ como também, com a posição das duplas ligações na cadeia carbônica ${ }^{54} \mathrm{~A}$ concentração de alquilésteres com alto grau de insaturação varia de acordo com a matéria prima utilizada na produção do biodiesel. Quanto maior o número de insaturações, mais susceptível está a molécula à degradação tanto térmica quanto oxidativa, formando produtos insolúveis que ocasionam problemas de formação de depósitos e entupimento do sistema de injeção de combustível do motor. Antioxidantes naturais dos óleos vegetais promovem uma maior estabilidade à oxidação (ex.: tocoferóis), no entanto, estes podem ser perdidos durante o processo de refino ou por degradação térmica. ${ }^{55}$

A alta temperatura e a exposição ao ar são fatores importantes que afetam a estabilidade do biodiesel, contudo, esta é significativamente afetada quando estes dois fatores estão presentes ao mesmo tempo. ${ }^{7}$ A presença de água no biodiesel pode também promover a oxidação (oxidação hidrolítica), no entanto, em menor extensão. A viscosidade, o índice de peróxido e, principalmente, o período da indução de Rancimat são parâmetros que podem ser utilizados para monitoramento da degradação oxidativa do biodiesel durante o período de estocagem.

O método Rancimat é aceito como padrão na norma EN 14214 e na RANP 07/08, para análise da estabilidade oxidativa do biodiesel (método EN 14112), com valor mínimo de período de indução de 6 h. Neste método, uma amostra do alquiléster (biodiesel) é mantida em um vaso de reação, a temperatura de $110^{\circ} \mathrm{C}$ e sob um fluxo de ar. Neste momento começam a se formar os peróxidos, que são os principais produtos formados na primeira etapa de oxidação do biodiesel. Com o processo de oxidação continuada, são formados compostos orgânicos voláteis, dentre estes, ácidos orgânicos de baixa massa molecular. Estes compostos são transportados pelo fluxo de ar para outro recipiente contendo água destilada, onde a presença dos ácidos orgânicos é então detectada pelo aumento da condutividade no sistema. O tempo decorrente até a detecção dos ácidos orgânicos é denominado de período de indução.

Um estudo de acompanhamento da oxidação do biodiesel metílico do óleo de soja foi realizado por Knothe. ${ }^{44}$ Neste trabalho, quantidades iguais de biodiesel foram colocadas em béqueres de diferentes tamanhos, variando a área de contato com o ar. As condições de oxidação estudadas foram: aquecimento a $80{ }^{\circ} \mathrm{C}$ por um período de $168 \mathrm{~h}$ e aquecimento a $165{ }^{\circ} \mathrm{C}$ por $3 \mathrm{~h}$. A oxidação do biodiesel foi acompanhada por ressonância nuclear magnética protônica (proton nuclear magnetic resonance - $\left.{ }^{1} \mathrm{H}-\mathrm{NRM}\right)$, que é específica para determinação dos ácidos graxos de cadeias curtas e para as alterações nas duplas ligações, ambos decorrentes do processo de oxidação do biodiesel. Foi observado que a taxa de oxidação do biodiesel aumenta com o tempo e com o grau de exposição ao ar. Resultados de ${ }^{1} \mathrm{H}$ RMN mostraram que o decréscimo da concentração de metil éster coincide com o aumento da concentração dos ácidos graxos de cadeia curta, com o valor de acidez e com o valor da viscosidade cinemática.

\section{Água e sedimentos}

A água, além de promover a hidrólise do biodiesel resultando em ácidos graxos livres, também está associada à proliferação de microorganismos, corrosão em tanques de estocagem com deposição de sedimentos. Como o biodiesel apresenta certo grau de hidroscopicidade, o teor de água deverá ser monitorado durante o armazenamento. Apenas a norma ASTM D6751 adotou o método ASTM D2709 para determinação de água e sedimento por centrifugação, estipulando um 
Tabela 4. Métodos multivariados para análise de biodiesel

\begin{tabular}{lll}
\hline Técnica & $\begin{array}{c}\text { Ferramenta } \\
\text { quimiométrica }\end{array}$ & Comentários \\
\hline
\end{tabular}

Comparação de vários espectros de transmissão NIR (7300-4300 $\left.\mathrm{cm}^{-1}\right)$ de amostras de óleo de

NIR PLS diferentes contaminantes (glicerina, metanol e ácidos graxos). Os sinais em 4425-4430 e em $6005 \mathrm{~cm}^{-1}$ foram utilizados na construção de um modelo de previsão Os melhores resultados foram obtidos quando se utilizou o sinal em $6005 \mathrm{~cm}^{-1}$.

Além dos picos obtidos no espectro NIR, foram monitorados também os sinais em ${ }^{1} \mathrm{H}$ RMN, NIR PLS sendo 3,7 ppm, correspondente ao singlete relativo aos prótons da metila dos ésteres metílicos, e 2,3 ppm relativo aos prótons metilênicos da porção alcoxi dos trilicerídeos. Conforme o autor, os resultados obtidos por NIR e ${ }^{1} \mathrm{H}$ RMN apresentaram boa correlação.

Monitoramento da cinética da transesterificação etílica do óleo de soja degomado. O melhor resultado foi obtido na região de $1700 \mathrm{a} 1800 \mathrm{~cm}^{-1}$, correspondente à mudança no estiramento

FTIR PCA e PLS vibracional $\mathrm{C}=\mathrm{O}$, que foi utilizada para construir o modelo de calibração multivariada, empregando o método PLS. Os resultados apresentaram pequena discrepância em baixas concentrações que foram atribuídas à presença de interferentes não modelados, no caso, mono- e di-glicerídeos.

Quantificação de misturas de biodiesel e óleos vegetais em diesel mineral. Foram preparadas amostras utilizando óleos de soja, de mamona, de fritura usado e seus respectivos ésteres. A

FTIR

NIR

PCA e PLS melhor região espectral NIR situa-se entre 2200 e 2280 nm. Já para FTIR a melhor região foi entorno do pico de absorção da carbonila, aproximadamente $1750 \mathrm{~cm}^{-1}$. De acordo com os resultados, as performances dos modelos de calibração NIR e FTIR foram muito parecidas.

Quantificação de metilésteres em misturas diesel/biodiesel, comparando modelos de calibração baseados em PLS e em rede neural artificial (Artificial Neural Network - ANN). Para previsão de ésteres metílicos nas amostras de mistura binária diesel/biodiesel, o modelo FTNIR/PLS foi o que demonstrou melhor desempenho. Quanto à modelagem utilizando ANN, as técnicas FTIR

FTIR ATR FTNIR PLS e ANN

e FTNIR apresentaram desempenho similar. Para misturas de diesel com três diferentes tipos de biodieseis, os modelos FTIR-ATR/PLS e FTNIR/PLS apresentaram similaridade na exatidão, contudo o modelo FTNIR/PLS foi mais preciso. Modelos baseados em ANN, tiveram desempenho similar. De forma geral, os modelos de previsão baseados no método PLS apresentaram melhor desempenho.

Modelos de calibração univariada e multivariada para monitoramento e quantificação de ésteres na transesterificação etílica do óleo de soja. O modelo de calibração univariada foi construído com base na correlação entre a massa do etil éster e a área integrada da banda em $2932 \mathrm{~cm}^{-1}$,

FTRaman PLS normalizada pela área integrada da banda em $3012 \mathrm{~cm}^{-1}$. Para análise mutivariada, foram avaliados cinco modelos de previsão baseados em FTRaman/PLS. Os melhores resultados foram obtidos para dois modelos de calibração que utilizaram normalização interna pela área integrada da banda de absorção em $3012 \mathrm{~cm}^{-1}$.

FTRaman

${ }^{1} \mathrm{H}-\mathrm{NMR}$

FTIR

FTIR ATR

PCA

HPLC

PLS
Os resultados de FTRaman/PLS, referentes ao trabalho anterior, ${ }^{62}$ foram comparados com três formas distintas de cálculos das concentração por ${ }^{1} \mathrm{H}$ RMN, obtendo uma boa correlação.

Previsão da viscosidade em biodiesel de mamona e em suas misturas com ésteres de outras PCA e PLS oleaginosas, onde a fração mássica do biodiesel de mamona variou de 0 a 100\%, em intervalos de $5 \%$. Os resultados obtidos apresentaram erros de previsão menor que $10 \%$.

Classificação de amostras de biodiesel de palma, algodão e mamona, na presença de adulterante óleo de soja refinado, nas proporções de 1 a $40 \%$.

Quatro tipos de redes foram avaliados na previsão do número de cetanos (Cetane Number$\mathrm{CN}$ ) em diferentes tipos de biodiesel, com base na sua composição de ácidos graxos determinada por HPLC. As exatidões dos modelos foram analisadas, obtendo valores muito próximos, variando de 3,4 a $3,8 \%$. Os modelos multivariados foram apresentados como alternativa ao método ASTM D611. no infravermelho próximo com transformada de Fourier)

${ }^{1}$ H-NMR - Próton Nuclear Magnetic Resonance (ressonância nuclear magnética protônica); LS - Luminescence Spectroscopy (espectroscopia de luminescência). 
Tabela 4. Continuação

\begin{tabular}{ccc}
\hline Técnica & $\begin{array}{c}\text { Ferramenta } \\
\text { quimiométrica }\end{array}$ & Comentários \\
\hline
\end{tabular}

Quantificação multivariada de água e metanol em biodiesel. O trabalho consistiu em avaliar a influência de diferentes técnicas de pré-processamento dos dados na construção dos modelos de NIR PCR e PLS previsão. Os melhores resultados foram obtidos com a aplicação da derivada de primeira ou segunda ordem de Savitsky-Golay seguida da estratégia de centrar os dados na média e correção de sinal ortogonal, antes da regressão por PCR e PLS.

${ }^{1} \mathrm{H}$-NMR $\quad$ PCA Análise exploratória de perfis espectrais de ${ }^{1} \mathrm{H}$ RMN para em misturas de biodieseis de palma, palmiste e maracujá com diesel mineral nas proporções de 2, 5 e $100 \%$.

Comparação entre métodos sem e com seleção de variáveis, para análise de biodiesel adul-

FTIR PLS terado com óleo de soja na proporção de 1 a $40 \%$ volume. Melhores resultados foram obtidos com seleção de variáveis.

Método de quantificação de biodiesel de mamona em diesel empregando banda de absorção no FTIR e LS PLS infravermelho em $1743 \mathrm{~cm}^{-1}$. Caracterização da mistura diesel/biodiesel/óleo vegetal por espectroscopia de luminescência, empregando bandas de emissão em $403 \mathrm{~nm}$ para o diesel e 673 para o óleo de mamona.

Comparação entre quatro modelos de calibração desenvolvidos com base em PRC e PLS, utili-

FTNIR

FT-Raman

PCR e PLS zando espectroscopia no infravermelho e espectroscopia Raman, para determinação de adulterações em misturas diesel/biodiesel. O modelo que se mostrou mais adequado foi o modelo PLS/ FTNIR

Identificação de adulteração do diesel por adição de óleos vegetais. Foram analisadas amostras de diesel com diferentes concentrações de biodieseis de mamona e de soja, óleos de soja e de mamona. As separações dos grupamentos se deram pela diferença de fluoróforos característicos de cada componentes das amostras. Foi possível identificar não somente a adição de óleo vegetal ao diesel como também grupos de amostras com alta e baixa concentração de biodiesel.

Previsão da composição do biodiesel em termos dos seus principais ésteres metílicos. Utilizou NIR PCA e PLS a região compreendida entre 9000 e $4500 \mathrm{~cm}^{-1}$ para determinação em amostras de biodieseis de diferentes oleaginosas, óleo de fritura e misturas.

Elaboração de modelo para previsão do índice de iodo, ponto de entupimento de filtro a frio, NIR PCA e PLS viscosidade cinemática a $40^{\circ} \mathrm{C}$ e densidade a $15^{\circ} \mathrm{C}$ em biodieseis de óleos de diferentes oleaginosas e suas misturas.

ANN - Artificial Neural Network (redes neurais artificiais); FTIR ATR - Fourier Transform Infrared - Attenuated Total Reflectance (espectroscopia no infravermelho com transformada de Fourier e refletância total atenuada); FTNIR - Fourier Transform Near Infrared (espectroscopia no infravermelho próximo com transformada de Fourier)

${ }^{1} \mathrm{H}-\mathrm{NMR}$ - Próton Nuclear Magnetic Resonance (ressonância nuclear magnética protônica); LS - Luminescence Spectroscopy (espectroscopia de luminescência).

valor máximo permitido de $0,05 \%$ volume. Tanto a RANP 07/08 quanto a norma EN 14214 adotaram o método coloumétrico (Karl Fischer) EN ISO 12937, com maior sensibilidade para determinar o teor de água, fixando a concentração máxima aceitável de água no biodiesel em 500 $\mathrm{mg} / \mathrm{kg}$. A norma brasileira também indica o método ASTM D6304.

\section{Índice de acidez.}

O monitoramento da acidez no biodiesel é de grande importância durante a estocagem, na qual a alteração dos valores neste período pode significar a presença de água. O método recomendado pela EN 14214 é o EN 14104, que utiliza uma solução alcoólica de KOH como titulante e fenolftaleína como indicador. A ASTM recomenda é o método potenciométrico D 664. Segundo Knothe, este método não apresenta boa reprodutibilidade e recomenda o método ASTM D974, que se baseia na titulação em sistema não aquoso e utiliza solução de $\mathrm{KOH}$ em isopropanol como titulante e p-naftolbenzoina como indicador. ${ }^{44}$ Conforme o autor, trata-se de um método mais indicado para análise de biodiesel. Os métodos adotados pela RANP 07/08 são os mesmos indicados pelas normas americana e européia, além do método de titulação potenciométrica ABNT NBR 14448. Todas as normas descritas acima estabeleceram limites máximos de acidez de $0,5 \mathrm{mg}$ de $\mathrm{KOH} / \mathrm{g}$.
Reda e colaboradores elaboraram um método de determinação de índice de acidez em biodiesel por ressonância nuclear magnética protônica. ${ }^{52} \mathrm{O}$ método proposto baseia-se na correlação linear entre os prótons olefínicos e alifáticos. Os resultados obtidos apresentaram boa correlação com valores determinados pelo método oficial. Devese, no entanto, levar em conta o custo de aquisição e manutenção do equipamento.

\section{Métodos analíticos multivariados na análise de biodiesel}

A evolução dos métodos analíticos instrumentais permite hoje a obtenção de um número muito grande de informações acerca da amostra analisada. Não por acaso, o desenvolvimento de técnicas estatísticas e matemáticas, aliado ao desenvolvimento indispensável de sistemas computacionais, tem acompanhado esta evolução, possibilitando o tratamento de grande quantidade de dados.

Embora as técnicas cromatográficas CGC, HPLC, SED e a RMN sejam técnicas instrumentais bastante estabelecidas, capazes de fornecer resultados de análise de biodiesel com precisão e exatidão satisfatórias, não podem ser facilmente aplicadas em determinações in situ para monitoramento da reação de transesterificação. ${ }^{56}$ Métodos espectroscópicos 
vibracionais, aliados à análise multivariada, têm sido estudados com o objetivo de estabelecer modelos de calibração. Estes apresentam vantagens de não serem métodos destrutivos, não necessitarem de reagentes e tratamento da amostra, de possuírem aceitável precisão e exatidão, serem rápidos e pouco laboriosos, ${ }^{57}$ além de poderem ser aplicados ao monitoramento in situ da reação de trasesterificação. ${ }^{58}$ Com o uso de ferramentas quimiométricas é possível extrair informações muito importantes e, muitas vezes, não perceptíveis numa análise visual de registros de espectros, cromatogramas ou outra propriedade medida (resposta instrumental). Outra grande vantagem é a aplicação na análise em matrizes complexas, ou seja, na presença de interferentes ${ }^{55}$ o que seria impraticável para a análise univariada sem tratamento prévio da amostra.

Os modelos de calibração multivariada, aqui apresentados (Tabela 4), não oferecem sensibilidade adequada à quantificação de contaminantes do biodiesel, na faixa limite de concentração dos parâmetros de qualidade. ${ }^{43}$ Por outro lado, as técnicas instrumentais associadas permitem uma rápida e fácil aquisição de dados que, quando tratados por análise multivariada, possibilitará a quantificação de analitos, mesmo na presença de interferentes. Estas são condições básicas para o monitoramento da reação de transesterificação in situ. O acompanhamento e o entendimento da cinética da reação de transesterificação são de extrema importância não só do ponto de vista acadêmico, como também da aplicação direta em otimização de processos industriais.

\section{CONSIDERAÇÕES FINAIS}

Para introdução de novos combustíveis automotivos na matriz energética é preciso estabelecer padrões de qualidade de forma garantir a segurança do consumidor, salvaguardar o motor e avalizar a qualidade das emissões da queima. Estes parâmetros estão associados a características químicas do combustível, que podem ser avaliadas através de métodos físico-químicos de análise. Desta forma, procurase conquistar a confiança do mercado e da indústria automotiva, garantindo o sucesso do novo combustível.

Parte dos métodos de análise físico-químicas do biodiesel são métodos clássicos bem estabelecidos para análise do diesel mineral. Os demais são métodos analíticos há muito tempo empregados na determinação da qualidade de óleos e gorduras. Pesquisas têm sido continuamente realizadas, na busca de métodos analíticos confiáveis, cada vez mais rápidos e, na medida do possível, de custo cada vez menor. Essa é uma tendência natural que tem ganhado mais força com a aplicação de métodos quimiométricos de análise de dados.

Métodos espectroscópicos aliados à análise multivariada têm sido propostos para análise do biodiesel. Embora ainda não seja possível aplicá-los na análise de contaminantes, presentes em nível de traço, têm sido apresentados como ferramentas úteis na determinação de outras propriedades e no estudo e monitoramento da reação de transesterificação. Considerando o contínuo avanço tecnológico e que poucos trabalhos utilizando análise multivariada foram apresentados, desde a primeira aplicação em $1999,{ }^{58}$ pode-se inferir que a análise multivariada tem um futuro muito promissor na determinação da qualidade do biodiesel.

\section{REFERÊNCIAS}

1. www.mme.gov.br, acessada em Dezembro 2006.

2. Trevisani, L.; Fabbri, M.; Negrini, F.; Ribani,P. L.; Energy Convers. Manage. 2007, 48, 146; Hamelinck, C. N.; Faaij, A. P. C.; Energy Policy 2006, 34, 3268.

3. Rinaldi, R.; Garcia, C.; Marciniuk, L. L.; Rossi A. V.; Schuchardt, U.; Quim. Nova 2007, 30, 1374; Demirbas, A.; Energy Convers. Manage. 2003, 44, 2093.
4. Lotero, E.; Liu, Y.; Lopez, D. E.; Suwannakarn, K.; Bruce, D. A.; Goodwin, J. G.; Ind. Eng. Chem. Res., 2005, 44, 5353; Ferrari, R. A.; Oliveira, V. S.; Scabio, A.; Quim. Nova 2005, 28, 19; Oliveira, J. S.; Montalvão, R.; Dher, L.; Suarez, P. A. Z.; Rubim, J. C.; Talanta 2006, 69, 1278.

5. Corrêa, S. M.; Arbilla, G.; Atmos. Environ. 2006, 40, 6821.

6. Lotero, E.; Liu, Y.; Lopez, D. E.; Suwannakarn, K.; Bruce, D. A.; Goodwin, J. G.; Ind. Eng. Chem. Res. 2005, 44, 5353.

7. Leung, D. Y. C.; Koo, B. C. P.; Guo Y.; Bioresour. Technol. 2006, 97, 250; Ma, F.; Hanna, M. A.; Bioresour. Technol. 1999, 70, 1.

8. Sharma, Y. C.; Singh, B.; Upadhyay, S. N.; Fuel 2008, 87, 2355; Bondioli, P.; Bella, L. D.; Eur. J. Lipid Sci. Technol. 2005, 107, 153.

9. Schuchardt, U.; Serchelli, R.; Vargas, R. M.; J. Braz. Chem. Soc. 1998, 9, 199; Edgar, L.; Liu, Y.; Lopez, D. E.; Suwannakarn, K.; Bruce, D. A.; Goodwin, J. G.; Ind. Eng. Chem. Res. 2005, 44, 5353.

10. Peter, S. K. F.; Ganswindt, R.; Neuner, H.; Weidner, E.; Eur. J. Lipid Sci. Technol. 2002, 104, 324; Xie, W.; Huang, X.; Catal. Lett. 2006, 107, 53; Kulkarni, M. G.; Gopinath, R.; Meher, L. C.; Dalai, A. K.; Green Chem. 2006, 8, 1056; Solhy, A.; Clark, J. H.; Tahir, R.; Sebti, S.; Larzek, M.; Green Chem. 2006, 8, 871; Furuta, S.; Matsuhashi, H.; Arata, K.; Biomass Bioenergy 2006, 30, 870; Shibasaki-Kitakawa, N.; Honda, H.; Kuribayashi, H.; Toda, T.; Fukumura, T.; Yonemoto, T.; Bioresour. Technol. 2007, 98, 416; Suarez, P. A. Z.; Meneghetti, M. R. M.; Wolf, C. R.; Quim. Nova 2007, 30, 667.

11. Ban, K.; Kaieda, M.; Matsumoto, T.; Kondo, A.; Fukuda, H.; Biochem. Eng. J. 2001, 8, 39; Zeng, J.; Du, W.; Liu, X.; Liu, D.; Daí, L.; J. Mol Catal. B: Enzym. 2006, 43, 15; Nie, K.; Xie, F.; Wang, F.; Tan, T.; J. Mol Catal. B: Enzym. 2006, 43, 142; Li, L.; Du, W.; Liu, D.; Wang, L.; Li, Z.; J. Mol Catal. B: Enzym. 2006, 43, 58.

12. Knothe, G.; Fuel Process. Technol. 2005, 86, 1059.

13. Morais, M. M.; Pinto, L. A. A.; Ortiz, S. C. A.; Crexi, V. T.; Silva, R. L.; Silva, J. D.; Revista Instituto Adolfo Lutz 2001, 60, 23; http://www.sbrt. ibict.br, acessada em Janeiro 2007.

14. Van Gerpen, J.; Fuel Process. Technol. 2005, 86, 1097.

15. Meher, L. C.; Sagar, D. V.; Naik, S. N.; Renewable and Sustainable Energy Reviews 2006, 10, 248.

16. Braun, S.; Appel, L. G.; Schmal, M.; Quim. Nova 2003, 27, 472.

17. Sobolev, E. P.; Churshukov, E. S.; Rozhkov, I. V.; Rubinshtein, I. A.; Chem. Technol. Fuels Oils 1966, 2, 648.

18. Anastopoulos, G.; Lois, E.; Karonis, D.; Kalligeros, S.; Zannikos, F.; Energy 2005, 30, 415.

19. Edlund, M.; Visser, H.; Heitland, P.; Anal. At. Spectrom. 2002, 17, 232.

20. dos Santos, E. J.; Herrmann, A. B.; Chaves, E. S.; Vechiatto,W. W. D.; Schoemberger, A. C.; Frescura, V. L. A.; Curtius, A. J. J.; Anal. At. Spectrom. 2007, 22, 1300.

21. Mittelbach, M.; Bioresour. Technol. 1996, 56, 7.

22. Bowman, M.; Hilligoss, D.; Rasmussen, S.; Hidrocarbon Processing 2006, 103.

23. Freedman, B.; Pryde, E. H.; Kwolek, W. F.; J. Am. Oil Chem. Soc. 1984, $61,1215$.

24. Freedman, B.; Kwolek, W. F.; Pryde, E. H.; J. Am. Oil Chem. Soc. 1986, 63,1370 .

25. Trathnigg, B.; Mittelbach, M.; J. Liq. Chromatogr. 1990,13, 95.

26. Mittelbach, M.; Chromatographia 1993, 37, 623.

27. Plank, C.; Lorbeer, E.; J. Chromatogr., A 1995, 697, 461.

28. Holcapek, M.; Jandera, P.; Fischer, J.; Prokes, B.; J. Chromatogr., A 1999, 858, 13

29. Foglia, T. A.; Jones, K. C.; Nuñez, A.; Phillips, J. G.; Mittelbach, M.; Chromatographia, 2004, 60, 305.

30. Arzamendi, G.; Arguiñarena, E.; Campo, I.; Gandía, L. M.; Chem. Eng. J. 2006, 122, 31.

31. Rezende, D. R.; Alves, M. I. R.; Antoniosi Filho, N. R.; I Congresso da Rede Brasileira de Tecnologia de Biodiesel: artigos técnico-científicos, Brasília, Brasil, 2006. 
32. Rezende, D. R.; Fleury Filho, N.; Antoniosi Filho, N. R.; II Congresso da Rede Brasileira de Tecnologia de Biodiesel: livro de resumos, Brasília, Brasil, 2007.

33. Jin, F.; Kawasaki, K.; Kishida, H.; Tohji, K.; Moriya, T.; Enomoto, H.; Fuel 2007, 86, 1201.

34. www.anp.gov.br/petro/legis_biodiesel.asp, acessada em Julho 2007.

35. Sturgeon, R. J.; Deamer, R. L.; Harbison, H.A.; J. Pharm. Sci. 1979, 68, 1064.

36. Lozano, P.; Chirat, N.; Graille, J.; Pioch, D.; Fresenius J. Anal. Chem. 1996, 354, 319.

37. Soloni, F. G.; Clin. Chem. 1971, 17, 529; White, D. A.; Miyada, D. S.; Nakamura, R. M.; Clin. Chem. 1974, 20, 645.

38. Catharino, R. R.; Milagre, H. M. S.; Saraiva, S. A.; Garcia, C. M.; Schuchardt, U.; Eberlin, M. N.; Energy Fuels 2007, 21, 3698.

39. http://www.methanol.org/, acessada em Janeiro 2007.

40. Gelbard, G.; Bres, O.; Vargas R. M.; Vielfaure F.; Schuchardt U.; . J. Am. Oil Chem. Soc. 1995, 72, 1239.

41. Neto, P. R. C.; Caro, M. S. B.; Mazzuco, L. M.; Nascimento, M. G.; J. Am. Oil Chem. Soc. 2004, 81, 1111.

42. Garcia, C. M.; Dissertação de Mestrado, Universidade Estadual de Campinas, Brasil, 2006.

43. Morgenstern, M.; Cline, J.; Meyer, S.; Cataldo, S.; Energy Fuels 2006, 20,1350 .

44. Knothe, G.; Eur. J. Lipid Sci. Technol. 2006, 108, 493.

45. www.blt.bmlfuw.gv.at, acessada em Janeiro 2007.

46. Faria, F. D.; Leal, G. P.; Cerqueira, K. O.; do Carmo, R. S.; Sant'Anna, D.; II Congresso da Rede Brasileira de Tecnologia de Biodiesel: livro de resumos, Brasília, Brasil, 2007.

47. Paraschivescu, M. C.; Alley, E. G.; French,W. T.; Hernandez, R.; Armbrust, K.; Bioresour. Technol. 2008, 99, 5901.

48. Oliveira, A. P.; Magalhães, A.; Dellatore, D.; Castro e Silva, E.; Antunes, K. C. P.; Villa, R. D.; II Congresso da Rede Brasileira de Tecnologia de Biodiesel: livro de resumos, Brasília, Brasil, 2007.

49. de Jesus, A.; Silva, M. M.; Vale, M. G. R.; Talanta 2008, 74, 1378.

50. Castilho, M. S.; Stradiotto, N. R.; Talanta 2008, 74, 1630.

51. Demirbas, A.; Fuel 2008, 87, 1743.

52. Reda, S. Y.; Costa, B.; Sossela, R.; II Congresso da Rede Brasileira de Tecnologia de Biodiesel: livro de resumos, Brasília, Brasil, 2007.

53. Peres, S.; Schuler, A.; Almeida, C. H. T.; Soares, M. B.; Campos, R.; Lucena, A.; II Congresso da Rede Brasileira de Tecnologia de Biodiesel: livro de resumos, Brasília, Brasil, 2007.

54. Bouaid, A.; Martinez, M.; Aracil, J.; Fuel 2007, 86, 2596.

55. Ferrari, R. A.; Oliveira, V. S.; Scabio, A.; Sci. Agi. 2005, 62, 291.

56. Zagonel, G. F.; Peralta-Zamora, P.; Ramos, L. P.; Talanta 2004, 63, 1021.

57. Ghesti, G. F.; de Macedo, J. L.; Braga, V. S.; de Souza, A. T. C. P., Parente, V. C. I.; Figuerêdo, E. S.; Resck, I. S.; Dias, J. A.; Dias, S. C. L.; J. Am. Oil Chem. Soc. 2006, 83, 597; Oliveira, F. C. C.; Brandão, C.
R. R.; Ramalho, H. F.; da Costa, L. A. F.; Suarez, P. A. Z.; Rubim J. C.; Anal. Chim. Acta 2007, 587, 194.

58. Blanco, M.; Beneyto, R.; Castillo, M.; Porcel, M.; Anal. Chim. Acta 2004, $521,143$.

59. Knothe, G.; J. Am. Oil Chem. Soc. 1999, 76, 795.

60. Knothe, G.; J. Am. Oil Chem. Soc. 2000, 77, 5

61. Pimentel, M. F.; Ribeiro, G. M. G. S.; da Cruz, R. S.; Stragevitch, L.; Pacheco Filho, J. G. A.; Teixeira, L. S. G.; Microchem. J. 2006, 82, 201.

62. Oliveira, J. S.; Montalvão, R.; Dher, L.; Suarez, P. A. Z.; Rubim, J. C.; Talanta 2006, 69, 1278.

63. Ghesti, G. F.; de Macedo, J. L.; Braga, V. S.; de Souza, A. T. C. P.; Parente, V. C. I.; Figuerêdo, E. S.; Resck, I. S.; Dias, J. A.; Dias, S. C. L.; J. Am. Oil Chem. Soc. 2006, 83, 597.

64. Ghesti, G. F.; de Macedo, J. L.; Resck, I. S.; Dias, J. A.; Dias, S. C. L.; Energy Fuels 2007, 21, 2475.

65. Sena Jr, F. C.; Lima, S. M.; Ferreira, C. V.; Pimentel, M. F.; Stragevitch, L.; I Congresso da Rede Brasileira de Tecnologia de Biodiesel: artigos técnico-científicos, Brasília, Brasil, 2006.

66. Soares, I. P.; Corgozinho, C. N. C.; Pereira, R. C. C.; Rezende, T. F.; Juliano, V. F.; Fortes, I. C. P.; I Congresso da Rede Brasileira de Tecnologia de Biodiesel: artigos técnico-científicos, Brasília, Brasil, 2006.

67. Ramadhas, A. S.; Jayaraj, S.; Muraleedharan, C.; Padmakumari, K.; Renewable Energy 2006, 31, 2524

68. Felizardo, P.; Baptista, P.; Menezes, J. C. M.; Correia, J. N.; Anal. Chim. Acta 2007, 595, 107.

69. Costa, D. J. L.; Flumignan, D. L.; Ferreira, F. O.; Tininis, A. G.; Oliveira, J. E.; II Congresso da Rede Brasileira de Tecnologia de Biodiesel: livro de resumos, Brasília, Brasil, 2007.

70. Soares, I. P.; Rezende, T. F.; Fortes, I. C. P.; II Congresso da Rede Brasileira de Tecnologia de Biodiesel: livro de resumos, Brasília, Brasil, 2007.

71. Hidalgo, F. P.; Rodrigues, C. V. L.; Miyai, I. H.; Brito, F. H.; II Congresso da Rede Brasileira de Tecnologia de Biodiesel: livro de resumos, Brasília, Brasil, 2007.

72. Oliveira, F. C. C.; Brandão, C. R. R.; Crhistian, R. R.; Ramalho, H. F.; da Costa, L. A. F.; Suarez, P. A. Z.; Rubim, J. C.; II Congresso da Rede Brasileira de Tecnologia de Biodiesel: livro de resumos, Brasília, Brasil, 2007.

73. Guimarães, A. K.; Musse, A. P. S.; Quintella, C. M.; II Congresso da Rede Brasileira de Tecnologia de Biodiesel: livro de resumos, Brasília, Brasil, 2007.

74. Baptista, P.; Felizardo, P.; Menezes, J. C.; Correia, M. J. N.; Anal. Chim. Acta 2008, 607, 153.

75. Baptista, P.; Felizardo, P.; Menezes, J. C.; Correia, M. J. N.; Talanta 2008, 77, 144. 